\title{
NOTAS SOBRE O CURRÍCULO COMO PRÁTICA DE TRADUÇÃO CULTURAL
}

\author{
Joyce Otânia Seixas RIBEIRO ${ }^{1}$ \\ Campus Universitário de Abaetetuba/UFPA \\ joyce@ufpa.br \\ Josenilda MAUÉS ${ }^{2}$ \\ ICED/UFPA \\ jomaues@ufpa.br
}

Resumo: $O$ artigo é parte de tese de doutorado, e tem a intenção de discutir a tradução cultural como ferramenta teórica. Para cumprir tal tarefa, faremos breve incursão teórica com a intenção de chegarmos à noção de tradução cultural de Bhabha (1998). Em seguida, acionaremos tal noção de tradução no debate curricular, com o intuito de delinear o currículo como prática de tradução cultural.

Palavras-chave: Cultura. Currículo. Tradução cultural.

Abstract: The article is part of a doctoral thesis, and intends to discuss the cultural translation as a theoretical tool. To fulfill this task, we will have a brief theoretical foray with the intention to get to the notion of cultural translation of Bhabha (1998). Then we will trigger such a notion of translation in curriculum debate, with the intention of outlining the curriculum as a practice of cultural translation.

Keywords: Culture. Curriculum. Cultural translation.

1 Professora Adjunta da UFPA/FAECS. Doutora em Educação pelo PPGED/ ICED/UFPA.

2 Professora do ICED/UFPA; líder do Difere - Grupo de Pesquisa Diferença e Educação. 


\section{Começando a experiência}

Este artigo é parte da tese de doutorado intitulada $A$ tradução da tradição em práticas curriculares no Colégio Estadual Paes de Carvalho ${ }^{3}$. O objetivo aqui é apresentar alguns aspectos do debate teórico sobre a tradução cultural, destacando como essa inovadora ferramenta pode ser útil e produtiva no campo curricular. Para cumprir tal tarefa, iniciaremos explorando as noções de tradução cultural para, em seguida, mostrar seu uso e muito brevemente seus efeitos no campo curricular.

\section{A tradução cultural como ferramenta analítica}

Não é nossa intenção traçar um apanhado sobre as teorias da tradução, mas tão somente esclarecer seu sentido e seu uso, no intuito de demarcar o modo como a acionamos no campo curricular; ainda assim, traçamos um breve trajeto teórico para chegar à apropriação diferenciada de Bhabha (1998).

Para Burke (2009), o estudo da tradução cultural por muito tempo ficou a cargo da Linguística e da Literatura. Porém, o refinamento do termo se deu no cruzamento desses com outros campos do saber, como a Antropologia, a História, a Filosofia, os Estudos Culturais, contando com as contribuições de Walter Benjamin, Jacques Derrida, Michel Foucault, Evans-Pritchard, Edward Said, Stuart Hall e mais recentemente o próprio Peter Burke e Homi Bhabha. No Brasil, Haroldo de Campos contribui com reflexões no campo da Literatura, seguindo os passos de Benjamin, porém, em um traçado bem original.

Desde o final do século XIX, a tradução cultural vem sendo utilizada pela Antropologia como um dos procedimentos do método etnográfico, sendo uma expressão “[...] originalmente cunhada por antropólogos do círculo de Edward Evan-Pritchard

3 Tese defendida em maio de 2013, no PPGED/ICED/UFPA, linha de pesquisa Educação: currículo, epistemologia e história, sob a orientação da Profa. Dra. Josenilda Maués. 


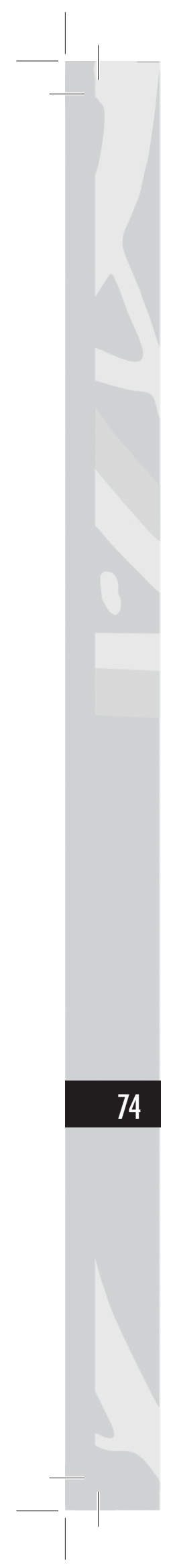

para descrever o que ocorre em encontros culturais quando cada lado tenta compreender as ações do outro" (BURKE, 2009, p. 14). Mas a expressão tradução é também usada no campo literário. Walter Benjamin se preocupou com a opção do tradutor quando esse traduz uma obra literária para outra língua. Para Benjamim, o tradutor precisa decidir: se transmite o conteúdo da obra garantindo a fluência do leitor ou mantém a originalidade da obra literária, sendo fiel a ela. No ensaio $A$ tarefa do tradutor (1923), Benjamin argumenta que a obra literária é uma obra de arte que precisa ter sua originalidade e continuidade garantida pelo tradutor, que precisa exercitar a liberdade e traduzir para sua própria língua, mas sem encobrir o original.

Outro campo de trânsito da tradução é o da historiografia, e aqui ainda se trata de tradução de obras escritas, porém, com outra conotação. A tradução cultural em Peter Burke é explorada no livro A tradução cultural nos primórdios da Europa moderna (2009), como sendo um processo interpretativo de objetos estrangeiros, entre os quais as obras escritas. O autor destaca a preocupação em traduzir textos históricos em conexão com outras línguas e outras culturas no período que compreende o início do Estado-Nação. O conceito de tradução cultural em Burke sofre os efeitos da contribuição de Evans-Pritchard, e tem a finalidade de compreender como as inúmeras traduções de obras escritas nas mais variadas línguas como o sânscrito, o pali, o árabe, o latim, o japonês e o chinês, contribuíram na veiculação de informação durante os séculos XIX e XX nos países europeus.

Para Burke (2009), é possível traduzir a linguagem técnica usada por advogados, médicos, cientistas, bem como a linguagem de leis, códigos e doutrinas religiosas, a moral e a ética, ideias, hábitos, tradições, costumes, o folclore, as imagens, as obras de arte e o artesanato, as imagens, filmes, rituais, festas, músicas, relatos orais, e símbolos. Há também uma poética no ato tradutório, pois há interesses políticos e estratégicos com certas finalidades, na medida em que uma cultura se interessa pela outra. Só não é passível de tradução línguas e culturas mortas, pois não há referentes, a partir de onde seja possível expressar influências e praticar o estranhamento, o que faz do ato 
tradutório uma miríade de estilos que podem envolver aceitação, negociação e resistência. Uma tradução pode, assim, ampliar, abreviar ou alterar o sentido do texto, por motivos políticos, sociais, morais ou religiosos. O fundamental para Burke (2009) é que a tradução seja realizada com liberdade, o que garantirá a criatividade do tradutor.

\section{A tradução cultural em Homi Bhabha}

As contribuições de Benjamim, Evans-Pritchard e Burke são fundamentais, porém, a tradução cultural recebeu um tratamento diferenciado nos Estudos Culturais. Aqui, a despeito das indispensáveis contribuições de Hall (1999) ${ }^{4}$, nos deteremos em Homi Bhabha, para quem a tradução não é unicamente uma atividade profissional - do pesquisador e/ou tradutor -, mas uma prática, possível para qualquer pessoa em certo ambiente cultural, inclusive, na escola.

Bhabha (1998) parte da justaposição cultural para compreender a tradução cultural como prática de aceitação, negociação, contestação e reinvenção cultural. Mesmo sofrendo os efeitos da teorização de Benjamin, sua noção de tradução cultural sofre as influências de, entre outros, Derrida, Foucault

4 Em Hall (1999), a tradução cultural é acionada para a compreensão do processo de constituição da identidade cultural no contexto da globalização cultural desde o início do século. $\mathrm{O}$ argumento do autor, é que o encontro entre várias culturas tem gerado um panorama de diásporas, fundamentalismo, nacionalismo e hibridismo cultural, com efeitos na identidade. $\mathrm{O}$ sujeito hoje vive entre tradição e tradução, entre passado e presente, entre local e global, entre suas raízes (tradição, mitos nacionais, particularismos) e os deslocamentos e as fragmentações da globalização. Nesse panorama, as identidades culturais são produzidas entre os movimentos de homogeneização e os de heterogeneização e, assim, jamais serão unificadas. As identidades, portanto, resultam do cruzamento de várias culturas, o que leva as pessoas a renunciarem à pureza, ao pertencimento ou à unidade (Cf. HALL, Stuart. A identidade cultural na pós-modernidade. Rio de Janeiro: DP\&A, 1999). 


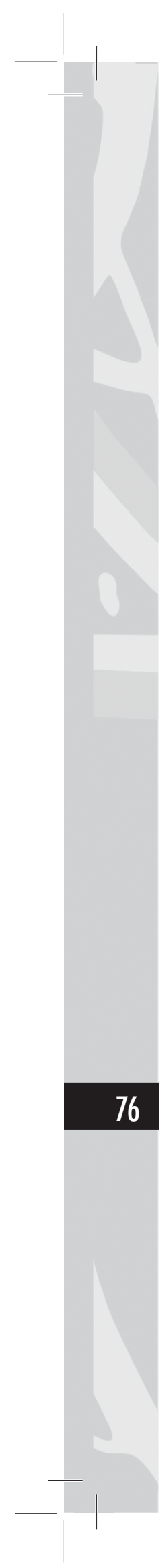

e Said. Essas influências o afastam dos enfoques literário, antropológico e historiográfico.

Bhabha (1998) desenvolve a tradução cultural considerando também o contexto pós-colonial, caracterizado pela globalização econômica e cultural, priorizando noções como nação, raça, hibridismo, diferença e agência. Considera ainda a desconstrução promovida pela virada linguística. Dessa, algumas noções servem de ancoragem para a tradução cultural, como a cultura tradutória, que é espaço de produção de significados atravessados por relações de poder - poder descentrado e difuso do modo como teorizado por Foucault (1997) - e a diferença; a realidade é considerada incoerente, desordenada e contingente, o tempo é não linear e não evolutivo, o espaço é assimétrico, o sujeito é descentrado, e os binarismos são diluídos, o que permite pensar a cultura como campo aberto, negociável e instável.

Essas noções distanciam o autor do realismo e do historicismo, da essência, da linearidade e da incessante busca da origem; o foco é o meio, o entre-lugar e o entre-tempo: espaços dispersos, difusos e disjuntivos; tempos ambivalentes, intervalares entre passado e presente. $\mathrm{O}$ entre-espaço e o entre-tempo são lugares estratégicos de enunciação e performances tradutórias. $\mathrm{O}$ espaço nunca é horizontal, plano, liso; a temporalidade não tem uma lógica causal e linear; há, portanto, uma dispersão do tempo e do espaço. Tempo e espaço múltiplos, cindidos, que confundem o tempo contínuo, e perturbam o ordenamento espacial.

Por conta disso, Bhabha (1998) - assim como Clifford (1998) - argumenta que no campo cultural não há consenso, unidade e coesão: há, sim, e fundamentalmente, ambivalências, conflitos e lutas por imposição de significados. Os conflitos resultam de justaposições conflitantes, tanto linguísticas quanto culturais, ambas comuns ao jogo entre culturas, o que leva Bhabha (1998) a recuperar o espaço intersticial, desprezado no processo de significação cultural ${ }^{5}$.

5 Bhabha (1998) pensa a cultura a partir da experiência pós-colonial marcada pelos deslocamentos de espaços e origens, pela escravidão, pelas diásporas 
Sua conclusão é que a cultura é uma construção híbrida condensada na expressão tradução cultural, na qual as diferenças e os conflitos não terão solução. Ambos, entre-lugar e entretempo só são possíveis devido a cultura ser tradutória, na medida em que exige de indivíduos e grupos, práticas de ressignificação dos símbolos e significados das culturas tradicionais - como literatura, arte, música, ritual, religião, costumes, habitação, alimentação, vestuário, festividades, etc. - que antes eram representadas por uma visão monolítica e homogênea de cultura como substantivo. As culturas são produções culturais; e a tradução revela a natureza múltipla e conflitiva dos significados, bem como a abertura, a hibridez, e a dinamicidade produzida pelos jogos de poder, pela diferença e pela alteridade.

A traduçãoéa ressignificação de símbolose/ou significados, praticada por homens e mulheres no espaço intersticial, criado no encontro entre culturas, entre local e global, entre passado e presente; e nesse processo manifesta-se uma multiplicidade de práticas materializadas em lugares nos quais se estabelecem novas estruturas de autoridade e iniciativas políticas, em que se alastram a ironia, a tensão e a mímica. Desse modo, a tradução cultural não é mera apropriação de aspectos de certa cultura, mas um processo que permite às pessoas avaliarem suas referências, significados, normas e valores, abandonando aquilo que é habitual e natural, e anexando o que é diferente e estranho; por isso, todo ato tradutório enseja ambivalência, antagonismo, conflitos, negociação entre significados e diferenças, revelando a incompletude de todo processo de tradução, especialmente quando se trata de processos educativos desencadeados nas instituições escolares.

Em Bhabha (1998), a tradução é um modo de refletir a cultura, por isso é preciso analisá-la em outros termos. Para o autor, a cultura é tradutória porque o espaço (território), as diásporas, os tempos, são marcados por histórias atravessadas pela diferença cultural. A tradução é assim o signo da diferença.

migratórias entre metrópole-colônia-metrópole, permitindo que reflita sobre a justaposição cultural e dê visibilidade ao hibridismo e a tradução. 


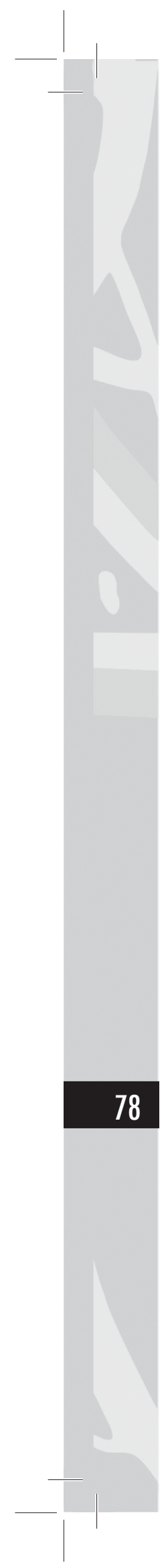

A diferença cultural não é apenas controvérsia e antagonismo, é mais que isso, pois por meio dela há um curtocircuito no tempo e no espaço de significação, por meio de práticas que recusam e rasuram, possibilitando a interconexão entre significados que são desse e de outro tempo e lugar. No ato da tradução há um estranhamento do conteúdo enunciado, e também o questionamento da autoridade, do poder colonial ou qualquer tipo de poder, logo, os movimentos de subversão e reinscrição exibem o caráter performático da cultura. Recontextualizamos essa noção de tradução cultural para escola, buscando compreender as práticas cotidianas juvenis como práticas curriculares de tradução cultural.

\section{0 currículo tradutório}

Acionando a noção de tradução cultural de Bhabha (1998) no campo curricular, faremos uma tentativa experimental de reflexão sobre o currículo como prática de tradução cultural. Acreditamos nessa possibilidade porque o currículo é um termo polissêmico e instável, que permite muitas experimentações, combinações e colagens. É também uma necessidade, porque no campo dos Estudos Culturais, as noções de currículo mais acionadas são a de currículo como política cultural e a de currículo como prática de significação e, mesmo que tenham em comum a ênfase no processo de significação, não trazem para o centro do debate o entre-lugar e o entre-tempo. Embora, Louro (2004) trate do entre-lugar no contexto do currículo queer, para discutir espaço de ação e expressão de sexualidades abjetas, no debate sobre tradução precisamos também do entre-tempo para discutir não só sexualidades, mas uma variedade de artefatos e práticas culturais.

Para interpretar as práticas curriculares de tradução cultural, acreditamos na necessidade de considerar o entrelugar e o entre-tempo pedagógicos, originados no encontro cultural no interior do colégio. Como zonas fronteiriças de ação pedagógico-cultural, ambos são lugares estratégicos para as práticas curriculares tradutórias, pois o espaço escolar não é 
plano, liso, assim como o tempo na escola também não é linear. Ambos são dispersos, múltiplos, divididos; eles hibridizam tempos pedagógicos e embaraçam a geometria espacial da escola, matizando a tradição cepeceana. Tendo clareza disso, não conseguimos deixar de pensar no currículo tradutório e essa iniciativa não pôde ser contida.

É preciso considerar as condições de possibilidade para pensar o currículo tradutório. Do ponto de vista contextual, a lógica cultural do capitalismo tardio e as marcas impressas pela globalização econômica e cultural. Do contexto epistemológico, o currículo é atingido pela crise da ciência moderna, o que gera a crise na teoria curricular crítica que, ficando com seu terreno desprotegido, permite a entrada de outras noções de educação, escola, conhecimento, sujeito, razão, tempo, espaço, realidade; noções mais abertas, fluidas e fragmentadas.

Não pretendemos explorar várias noções de currículo até chegar ao currículo tradutório, pois há vasto material sobre o tema ${ }^{6}$. Vamos logo entrar no debate sobre cultura e escola, dizendo que, desde o início da sociedade moderna, a escola é o lugar da diversidade, logo, ambivalente, pois sempre recebeu as mais variadas culturas - erudita, popular, folclore, midiática - todas matizadas pelas diferenças de classe, geração, gênero, sexualidade, raça, nação e religião.

Reforçando o encontro cultural na escola, Pérez Gómez (2001) argumenta que a escola é um espaço onde as culturas se misturam, fazendo da vida escolar um "[...] vivo, fluido e complexo cruzamento de culturas" (2001, p. 17). A cultura escolar é, assim, constituída por significados expressos no cotidiano escolar, nas rotinas, nos rituais, nas regras, nas condutas, nos costumes, nos valores e nos sentimentos.

6 SACRISTÁN, José G. O currículo: uma reflexão sobre a prática. Porto Alegre: ArtMed, 1998; APPLE, Michael W. Ideologia e Currículo. São Paulo: Brasiliense, 1982; GIROUX, H. Teoria crítica e resistência em educação. Petrópolis: Vozes, 1986; SANTOMÉ, Jurjo T. O curriculum oculto. Porto: Porto Editora, 1995; SILVA, Tomaz T. Documentos de Identidade: uma introdução às teorias do currículo. Belo Horizonte: Autêntica, 1999. 


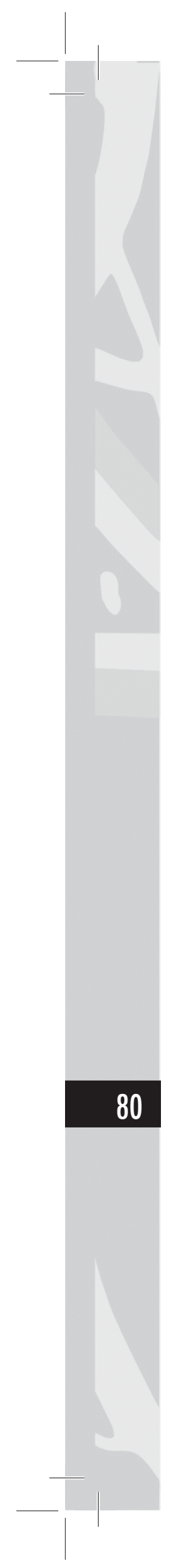

Considerando o encontro cultural na escola, o currículo não pode ser tão somente grade ou desenho curricular, ou o curriculum vitae onde se registra a vida escolar; o currículo, ainda, não tem apenas objetivos pedagógicos - a instrução, por meio da transmissão de fatos e saberes objetivos, com vista à perpetuação da cultura erudita -, mas tem também objetivos econômicos, políticos e culturais. Para Larrosa (1998), o currículo é um campo de produção de normatividade social e individual, que tem como função regular e disciplinar os corpos e as mentes dos sujeitos escolares, por meio de discursos sobre as formas politicamente sancionadas, fazendo com que sejam o que são. O currículo, assim, produz identidades e subjetividades.

Nessa direção, o currículo tem seu sentido expandido, compreendendo a arquitetura, a espacialização, as relações de poder, os discursos, as normas, o uniforme escolar, o regimento escolar, o Projeto Político Pedagógico, as datas comemorativas e festivas, enfim, toda a cultura escolar (SILVA, 1999). São práticas curriculares, o faladopensadovivido no cotidiano da escola. Tudo o que envolve a arte do fazer diário, de homens e mulheres no espaço escolar: o que pensam e sentem, o que falam, os modos como ocupam o espaço, o modo como usam as roupas e o uniforme escolar, a forma como organizam os eventos escolares, o que comem, os valores pedagógicos aceitos e contestados, suas condutas e atitudes, seus gestos, enfim, todo o ritual pedagógico-administrativo.

$\mathrm{Na}$ escola, um microcosmo da sociedade, o encontro cultural faz circular múltiplos significados diariamente, que são aceitos, contestados, negociados e reinventados conforme a identidade e subjetividade dos sujeitos escolares. Assim, à semelhança do que ocorre com a cultura que é permanentemente traduzida, a cultura escolar também o é. Se na arena cultural, a tradução se dá por meio de práticas culturais, na arena escolar a tradução se dá por meio de práticas curriculares, também residuais e emergentes, que recusam certos significados da cultura escolar instituída e os reeditam, materializando-os em suas fronteiras, no espaço de experiências possibilitado pelo encontro cultural. Mas afinal, o que é traduzido na escola? Qualquer artefato ou 
significado da cultura escolar que resulte do encontro entre duas ou mais culturas. Os artefatos e significados culturais são aceitos, negociados e contestados, por meio de práticas curriculares tradutórias, em movimentos ora harmônicos, ora conflituosos.

O sujeito das práticas curriculares tradutórias professores e professoras, funcionários e funcionárias, alunas e alunos - é constituído por identidades e subjetividades marcadas pelas diferenças de geração, gênero e sexualidade, 0 que implica uma infinidade de posições-de-sujeito, definidas temporariamente por interesses efêmeros e relações de poder.

Seguindo Hall (1999) e Bhabha (1998), o encontro cultural na escola faz surgir o entre-lugar pedagógico, no qual circulam diferentes e conflitantes significados. O sujeito se movimenta entre homogeneização e heterogeneização, logo, não é unificado. Esse cruzamento cultural leva o sujeito escolar a renunciar ao pertencimento, à unidade e a se movimentar no terreno da fragmentação e da diferença, se deslocando entre passado e presente. Esses sujeitos, de certo modo traumatizam a tradição, pois passam a habitar dois lugares, a aceitar significados conflitantes e negociar com eles. Os sujeitos escolares oscilam entre dois tempos e dois espaços, alguns momentos em harmonia, em outros, em curto-circuito. Ao final de acordos e negociações, os sujeitos escolares também estão traduzidos. Mas isso não quer dizer que o sujeito moderno sumiu. $\mathrm{O}$ sujeito traduzido, fragmentado, descentrado, convive lado a lado com o sujeito moderno, autônomo, centrado, racional e livre.

No caso do CEPC, o encontro cultural entre a tradição e as diferenças, abre caminho para a emergência do "fio cortante da tradução e da negociação, o entre-lugar" (BHABHA, 1998, p. 69), espaço do meio entre duas ou mais culturas, lugar de práticas que pode até parecer que são isoladas e desarticuladas, mas coladas adquirem sentido, pois pronunciam que a cultura é aberta, logo, a tradição não é original, pura, unificada, muito menos teleológica, um marco final.

Esse modo de pensar o currículo permitiu explicar a cultura do Colégio Paes de Carvalho que tem em seu centro a tradição cepeceana, possibilitando ao olhar mais detido visualizar 


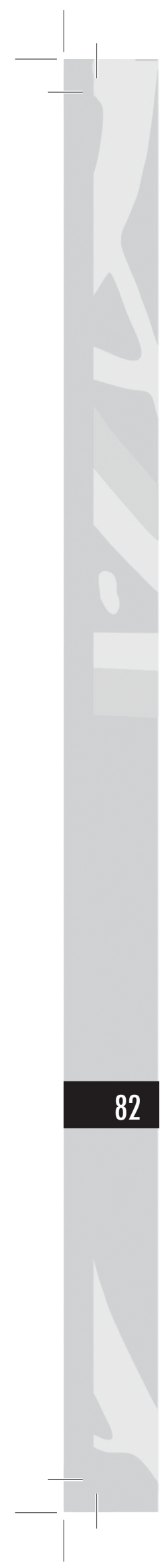

práticas de aceitação, negociação e contestação em relação a ela, e que refletimos como sendo práticas curriculares tradutórias. Assim, percebemos que três elementos da tradição cepeceana são contestados. Assim, mesmo que a arquitetura neoclássica centenária seja reverenciada com a aceitação tácita das escadarias generificadas, os alunos e alunas traduzem a arquitetura e a espacialização e produzem outros espaços de convivência, como a mureta e o balcão da lanchonete desativada. Mesmo com a defesa da tradição do uniforme escolar, as Belíssimas, customizam e atualizam o uniforme de normalista, acarretando conflitos cotidianos, devido à suposta erotização de seus corpos. À tradição dos jogos estudantis e do desfile escolar do passado, as Lorranys, um grupo de alunos gays, ocupam o espaço desses eventos escolares com espetáculos drag queens. Essas práticas curriculares de tradução da tradição ocorrem cotidianamente possibilitadas pelo encontro cultural entre os significados da tradição e os da diferença, no encontro entre significados do passado e do presente, e que passam a ocupar o entre-lugar pedagógico.

\section{Considerações finais}

As iniciais contribuições de Benjamim e Evans-Pritchard mantiveram a tradução cultural no foco de muitos estudos literários e antropológicos. Entretanto, não demorou para que fosse apropriada de modo diferenciado pelos Estudos Culturais, particularmente por Homi Bhabha (1998). Em Bhabha (1998), a tradução não consiste unicamente em atividade profissional do pesquisador e/ou tradutor -, mas é praticada por qualquer pessoa em certo ambiente cultural.

Para que as práticas tradutórias se efetuem, é preciso haver a justaposição cultural que pode se fazer presente em qualquer ambiente cultural, inclusive na escola. No contexto escolar, uma das expressões da tradução é o currículo, que tem seu sentido ampliado, compreendendo um conjunto de práticas e de significados escolares.

Seguindo Bhabha (1998), o encontro cultural na escola faz surgir o entre-lugar pedagógico, no qual o sujeito se movimenta, 
e o faz entre homogeneização e heterogeneização, passado e presente, habitando dois espaços a um só tempo, e aceitando, contestando, negociando e reinventando significados conflitantes, oscilando entre momentos harmoniosos e conflituosos. $\mathrm{O}$ currículo tradutório possibilita a tessitura de práticas que são irônicas e lúdicas, difíceis de ser controladas e/ou impedidas. A noção de currículo como prática de tradução cultural se mostra bastante útil na análise e explicação de certos problemas culturais presentes no cotidiano da escola, especialmente, de práticas culturais que abalam e chocam a autoridade cultural, porque inusitadas, estranhas e até inaceitáveis.

\section{REFERÊNCIAS}

BHABHA, Homi K. O local da cultura. Belo Horizonte: Editora UFMG, 1998.

BRITZMAN, Deborah. Curiosidade, sexualidade e currículo. In: LOURO, Guacira L. (Org.). O corpo educado: pedagogias da sexualidade. Belo Horizonte: Autêntica, 1999.

BURKE, Peter; HSIA, Ronnie Po-Chia. (Org.). A tradução cultural nos primórdios da Europa Moderna. Tradução Roger Maioli dos Santos. São Paulo: Editora UNESP, 2009.

CLIFFORD, James. A Experiência etnográfica: antropologia e literatura no século XX. Rio de Janeiro: Editora UFRJ, 1998.

FOUCAULT, Michel. Vigiar e punir. Petrópolis: Vozes, 1997.

HALL, Stuart. A identidade cultural na pós-modernidade. Rio de Janeiro: DP\&A, 1999.

LARROSA, Jorge. A construção pedagógica do sujeito moral. In: SILVA, Tomaz T. (Org.). Liberdades Reguladas: a pedagogia construtivista e outras formas de governo do eu. Petrópolis: Vozes, 
1998.

LOURO, Guacira L. Um corpo estranho: ensaios sobre sexualidade e teoria queer. Belo Horizonte: Autêntica, 2004.

PÉREZ GÓMEZ, Angel I. A cultura escolar na sociedade neoliberal. Tradução Ernani Rosa. Porto Alegre: ARTMED Editora, 2001.

SILVA, Tomaz, T. O currículo como fetiche: a poética e a política do texto curricular. Belo Horizonte: Autêntica, 1999. 